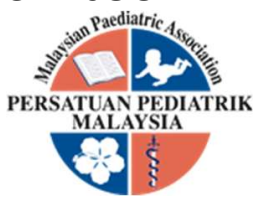

\title{
ANALYSING DRAWING IN NON-DIRECTIVE PLAY: A CASE OF 6-YEAR- OLD GIRL WITH EMOTIONAL PROBLEMS
}

\begin{abstract}
Azizah Othman ${ }^{1,2}$
ABSTRACT

Behavioural and emotional problem is commonly reported in childhood, some cases require psychological management. Non-directive therapeutic play or child-led play that always involve spontaneous drawing, is one of the most natural and potential means to work with children, yet it is not being fully utilised and explored. This is a single case study, of a 6-year-old girl, referred for therapeutic child-led play skill session for being easily irritable and aggressive at home. Following 20 sessions with a trained therapeutic play practitioner, mother reported marked improvement in her child's emotional regulation. We explored the child's emotional standing when she was drawing, as well as the changes that evolved as we analysed series of drawings she produced throughout the therapy. We conclude that careful analyses of spontaneous drawing, coupled with in-session behavioural observation, and reflection, emotional state of the child can be tacit. This information is consistent with parent-reported scoring.
\end{abstract}

Keywords: Emotional problem, children, nondirective play, spontaneous drawing, drawing analyses.

DOI: $10.51407 / m j p c h . v 27 i 2.149$

\section{Introduction}

Play is children's' main, natural activity through which they could potentially heal from emotional disturbances, when therapeutically supported by play therapist [1]. Non-directive therapeutic play is a form of therapy where the child leads the play and does not receive direction from the therapist regarding what, how, and when to do things in the playroom. On the other hand, children are engaged by therapist in warmth and friendly manner, accepted non-judgementally, given freedom and responsibilities to make choices, and reflected upon to gain insight of their own actions [1,2]. Following the Axline's principles, children decide what they like to do, except for very minimal and necessary safety boundaries, to promote full self-acceptance and responsibility [2]. Play therapy is theoretically framed to approach the child in a holistic manner using integrative techniques combining multiple play activities including creative visualisation, storytelling, drama, puppets and masks, dance and movement, music, sandplay, art, and drawing [1].
Received: 25 February 2021; Accepted revised manuscript: 07 November 2021

Published online: 06 December 2021

Many children engage in spontaneous drawing as it serves as a mean of communication and emotional expression when verbal language is limited [3]. Serial drawing as a therapeutic approach based on Jungian concept involves having a child produce drawing over time, therefore a therapist could view the child's inner world $[4,5]$. As the child draws, he works through his internal and external struggles which Jung (1931), who pioneered in spontaneous and semidirected drawing, believed self-realisation could be achieved [6]. Jung (1931) examined the archetypes within arts and discovered the symbols appeared in drawings signify the psyche's (i.e. individual being's) effort to grow and heal $[7,8]$. Jung continued that spontaneous drawing allows the child to express their

'Department of Paediatrics, School of Medical Sciences, Health Campus, Universiti Sains Malaysia, 16150 Kota Bharu, Kelantan, Malaysia

${ }^{2}$ Hospital Universiti Sains Malaysia, Kubang Kerian, Kelantan, Malaysia Corresponding Author:

Assoc. Prof. Dr. Azizah Othman, Department of Paediatrics, School of Medical Sciences, Health Campus, Universiti Sains Malaysia, 16150 Kota Bharu, Kelantan, Malaysia

Tel.: +6097676525 Email: azeezah@usm.my 
thoughts and feeling in non-threatening and safe condition [8]. When a child frees to choose what, when, and how to draw their pieces, it too promotes self-control and mastery [7,8], eventually self-changes and improvements. Emotional problems are symbolically expressed in drawings, whereby healing and resolution of internal conflicts could occur. These processes happen when trusting, therapeutic relationship is formed between a child and therapist [9]. Jungian therapist does not analyse the child's images in the session but rather encourage the child to freely draw as they wish, allow the child to fully absorb with the image making towards selfhealing, and links the meaning of the symbols in the drawing to the child's real outer world [4]. In short, drawing provides a space for safe expression and exploration of emotions connected to the child internal struggles which then exhibited in forms of outer behaviour [10]. When a child decides what to play in the playroom, drawing is one of the popular choices. Many view this spontaneity as central to the art therapy process [3,11-13], thus the outcomes (i.e. pieces of drawing) are worth analysed. Unlike Freudian psychoanalysis, Jungian drawing are not interpreted or analysed for the children. Yet therapist analyses the drawings to help them to be aware of the children's conscious and unconscious experiences that have emerged and are emerging through times and to be reflective upon it. This involves subjective evaluation and several attempts have been made to guide the analyses [14-16].

This report aims to analyse series of impromptu, child-initiated, and non-guided drawings, produced by a child who attended non-directive therapeutic play sessions, to see if there are any changes in emotions or self-improvement when they were externalised in the drawing symbols, through times.

\section{Method}

Subject

AA is 6-year-old Malay girl, who was self-referred by the mother for therapeutic child-led play skill session at Psychology Clinic in one of teaching hospitals in Kelantan for being easily irritable and aggressive at home.
Pre-assessment

Child's psychological functioning was assessed via The Strengths and Difficulties Questionnaires (SDQ) - Malay version [17] at the initial and final session, by AA's mother and class teacher. The SDQ consists of 25 -items covering five domains: emotional symptoms, conduct problems, hyperactivity, peer problems, and pro-social behaviours which are scored based on a Likert scale, with 5 items in each domain. The scores in the first four domains when added together would yield Total Difficulties scores. The cut-off measure indicating problems in the clinical range [18] are scores above the 90th percentile for the Total Difficulties domain (i.e. in which $80 \%$ of the children in the community are normal, $10 \%$ of children are in the 'abnormal range' and a further $10 \%$ are in the 'border line range'). Except for ProSocial Behaviour, higher scores indicate more problematic behaviour. The SDQ-Malay version is a reliable scale with Cronbach Alpha was acceptable for all parent, teacher and child-report data with values of $0.74,0.77$ and 0.78 , respectively [17]. Factor analysis of the parent's report showed a fivefactor solution, which was consistent with other psychometric evaluations of the SDQ in other languages. CFA showed good model fit of the original five factor model as mentioned above [17]. The pre assessment scores revealed a total of SDQ from mother and teacher were 13 and 7, respectively, which were within an average range (i.e. 0-13) suggesting that clinically significant problems in this area are unlikely, thus psychiatrist referral is not indicated.

\section{Case conceptualisation}

Upon intake interview with the mother, the case was conceptualised and the child's suitability for the intervention was established. The presenting problems related to mainly behavioural and emotional concerns with mild to moderate level of intensity, affecting some part of daily functioning and disturbing others, yet not severe enough to warrant psychiatric diagnosis. Mother reported significantly more difficult behaviour, as compared to class teacher.

AA is a 6-year-old Malay girl, a middle child of three siblings, the eldest is 7 and youngest being 5. Her father is a teacher and the mother is a lecturer. She lives with all family members, in addition to a-25-year-old uncle. She went to a private kindergarten since she was 4-year-old. At the same year her father had eventually 
transferred work from suburb area to the city, so that he could live together with the family, rather than spending time with AA during weekend only

At school, her class teacher identified AA as a good student who always completed her work in time. She had never created problems with peers. AA was quiet, preferred to be on her own, and had little interest to socialise. The teacher concerned of her frequent school absenteeism for no legitimate reason.

Contrary, mother claimed AA was an angry and aggressive girl, with constant outburst. Despite experiencing normal developmental milestones, AA was said to be hot tempered since young. Being a middle child with one year gap between siblings could possibly result in limited, divided parental attention. Absence father figure during early childhood phase, frequent changing of helpers, and very occupied, stressful working mother who enrolled in postgraduate study at the same time, could also predispose the child's problems. Being at home, tired, and presence of mother often trigger AA's problematic behaviour. Every day, AA never failed to make a 'scene' and displayed difficult behaviour. She picked fight with her siblings such as disturbing her bother when he does schoolwork or snatching her sister's toys during play. When things did not go her way, she cried loudly, threw tantrums, hit, and scratched others, including her mother and their former helpers. She refused to obey instructions and help with house chores. AA also used harsh and unkind words towards elderly whom she dislikes. Sometimes mother felt uncomfortable when relatives argued that $A A$ was spoiled. At times AA was punished for her wrongdoing, such as being pinched or canned by mother. Consequently, AA turned out more aggressive and hit the mother even more. On the other hand, father was stated as distant, and uninvolved, thus AA never created problem with him. AA was also said to be a kind, considerate girl when she wants to, or in a good mood.

\section{Intervention Plan}

Mother who was concerned that her daughter will grow up being an aggressive, unhappy child, self-referred AA for therapeutic play session which was offered via Psychology Clinic at the teaching hospital where mother was working at. The therapist, a consultant clinical psychologist, is also a certified practitioner in therapeutic play skills trained in therapeutic play by Academy of
Play and Child Psychotherapy (APAC) - a professional training course recognised by Play Therapy UK and Play Therapy International [19]. Upon description of therapeutic play and its potential, both therapist and mother agreed to commit in moderate-term child-lead therapeutic play session that consisted of $20 \times 40$ minutes weekly meetings. Whilst the mother's aimed for the child to stop hitting others, coping with anger, becoming less aggressive and more sociable upon session completion, the current report chooses to analyse the child's spontaneous drawings and examine for evidence in selfchanges illustrated in symbolic artistic manner, as the session was terminated.

\section{Session summary}

The first session was conducted in mid-April and AA completed her $20^{\text {th }}$ sessions in early November of the year. Except for some rescheduling due to unavoidable circumstances, AA attended all planned sessions punctually. Overall, she engaged in various child-directed play activities such as sand-play, role-play, clay, puppets, therapeutic storytelling, games, painting and drawing, most of the time on her own. In summary, the initial sessions were challenging that she took several sessions to develop trust and engage with the therapist. For example, she remained quiet, non-responsive and uninterested in the earlier sessions. The play was unplanned, and she shifted quickly from one form to another. There was time when conflict occurred, and boundary was tested. The child dissatisfied over things, became angry and hit the therapist. As she checked and experienced therapist's consistent, predictable nonjudgemental reactions, child's changes in behaviours and reactions in the sessions were slowly observed. Following this incident, AA appeared more relaxed and freer at play. Gradually she learned to understand both therapist's and her roles and benefited from it. Details description of each session is however beyond the scope of this report as we aim to analyse selective drawings produced by $A A$ and to understand the processes, she might have experienced from them.

\section{Analysis Plan}

We analysed and discussed the outcomes of one form of play activity that AA engaged in the session which is drawing. Drawing is chosen because it provides some concrete evident for 
analysis despite applying non-directive approach, as compared to more subjective play outcomes such as child movement, role-play, arts, and music. As spontaneous child-led activity, there was no cue or instruction given to the child to draw neither specific techniques should be applied onto the drawing. Three drawings available thus chosen to be analysed.

\section{Results and Discussion}

We present and discuss the results of the drawing analyses. Figure I, II, and III were produced by AA in session 5, 11, and 16 respectively. These drawing illustrate her emotional state that have evolved from a limited, frantic condition at starting point, into more adjusted as the sessions ensued.

The human figure drawing in Figure 1 was produced during initial session (i.e., Session 5) and it portrays insecurity. From a developmental perspective, a stick-like person is cognitively and emotionally limited, for a 6-year-old girl. The stick-like arms, legs, and omission of nose, ear, hands and feet suggest themes of lacking security, limited social interest, and communication difficulties [16]. These are true to describe AA especially at the earlier sessions. She chose to remain silent in the first 3 sessions. Later she communicated mainly using body language and gestures. She used harsh words with highpitched tone when she wanted something, suggestive lack of interpersonal skills.

Omission of the nose signals feeling of powerlessness and withdrawal. The omission of feet on Figure 1 too suggests an interesting analysis consistent with $A A^{\prime}$ 's current emotional condition which were feeling insecure and helpless [16]. Understandably many children share similar feelings in the initial sessions with stranger. Correspondingly, acting out and being aggressive at home may indeed her efforts to gain control over general feeling of powerlessness.

Special emphasis given to extraordinarily long hair suggested her need to be seen and cared for [16]. The long hair parsed down beyond her feet indicated her needs to be noticed was real and important. This may also suggest a self-centred personality [14] that fitted this child well at this time.
This drawing was lack of details. AA used only two-colour pens- yellow and blue - with no shades of colour noticed. Colour is used to release different emotions and a medium to balance the emotions too [16]. A limited use of colour suggested the child chose not to bring her emotions up as yet, neither that she was ready to do anything about her feelings. The thin lines and strokes as well as a seemingly light pen pressure suggested the child's low or reduced energy level as well as inner tendency to withdraw from social relationships [14].

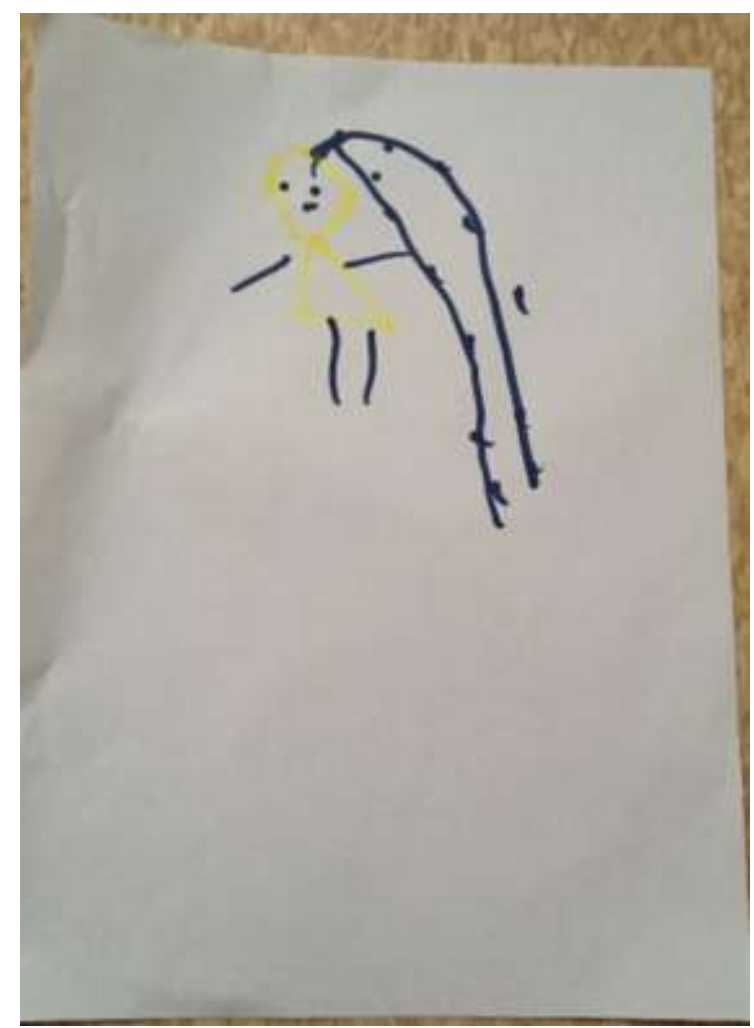

Figure 1. Child's drawing at the early phase of the session

Despite her resistance in the session, AA was hopeful. She turned up in all sessions although mother reported several times she refused to come. This is consistent with the placement of the figure in the upper half of the paper indicates optimism and fantasy [16]. Half-way through the sessions, therapist observed AA engaged in new, unique play where she brought herself in fantasy and magical world. She acted out as a magical princess or a butterfly with special power on others. Finally, a moderate-size figure positioned right in the middle of upper half of the paper suggested that AA had sufficient level of selfesteem and this was good prognostic factor. 
Figure 2 was drawn in the middle of the therapy (i.e. Session 11) - one after another. A house or building informs one's family dynamics such as relationships with and attitude towards family members, as well as internal issues. House indicates too the inner self a child - such as ego strength, vulnerability, openness and degree of rigidity [15]. Images in Figure 2 suggest a hopeful theme.

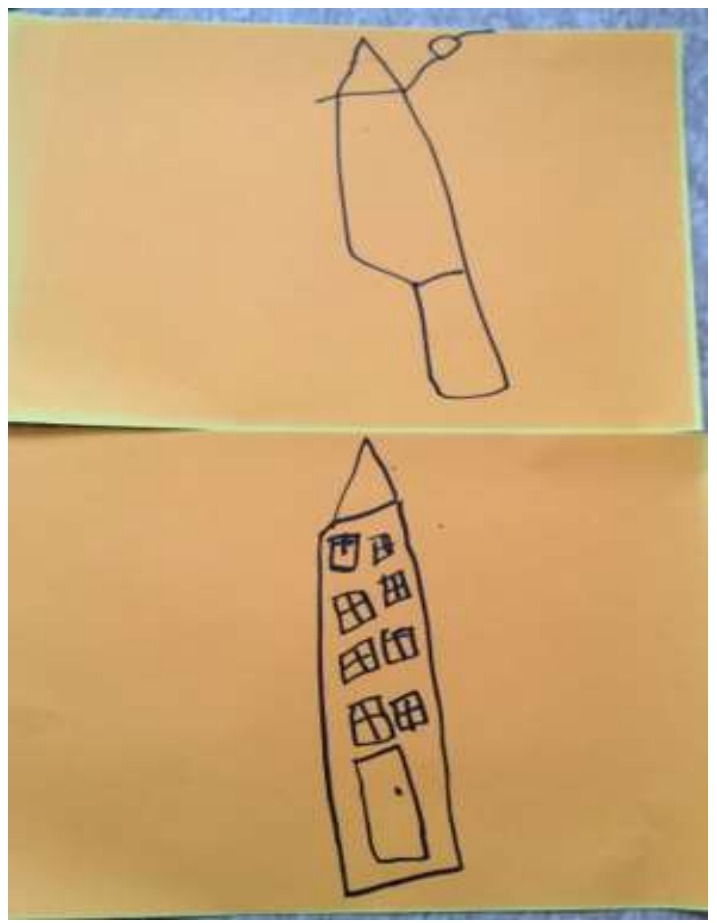

Figure 2. Child's drawing at the middle phase of the session

The first house drawn on the top is simple. It may represent $A A^{\prime}$ 's current state of self. A moderatesize house positioned approximately in the middle of the paper indicates adequate confidence level. The plain, solid wall suggests her firm ego strength that she believes in herself and has confidence in her actions [16]. There is a line separating the house into two parts. The upper, bigger but seemingly unbalanced part may suggest child's projective self. The self that she presents to the outside world - AA that we know. Whilst always been seen as a dominant who 'rules' the house with her misbehaviours, the child indeed shakes as the ground is smaller in surface to contain her huge projective self.

On the other hand, the bottom, smaller yet balanced part of the house may represent her-self at sub-conscious level. Her sub-conscious personality appears more stable, yet is not connected at all to her conscious, projected self. Thus, AA may not be aware of her inner, deeper needs and wants because there is no way information from this level could get through to her consciousness and awareness. As there is no way to get into the house, such as door or window, seemingly, there is no opportunity for anyone or anything outside to enter into the child's inner world - that she is psychologically inaccessible. A small-triangle shaped roof represents the child's fantasy [15] which is not big in size. There is something coming out from the roof that may indicate something is leaving out of the house, or something inside is made known to the public.

The second house in the bottom was swiftly drawn after. This house may signify child's hope to herself and to connect with others. The house feels close to the viewer that is may indicate child's willingness to open up and be psychologically accessible [15]. A medium-size, tall and proud house positioned right in the middle of the paper may suggest a well-balanced, adequate level of self-confidence, as indicated from the first house. A firm, unhesitant stroke suggests a persistent and ambitious person she is or she wants to be. Interestingly, AA's house is a big, tall building with no separated parts except for the roof, with a door and windows.

The door suggests child's readiness to establish connection with environment and allow others entering and influencing her world. The closed door with a knob indicates the concerned of risk and challenges to establish interpersonal relationships. Similarly, windows signify consistent themes of social accessibility. A seemingly large number of windows in the picture indicates the child's desire to expose or draw attention to self. Being in the middle of three siblings of one-year gap each, and now mother is expecting to have a new baby, it is reasonable to feel left out or insignificant, thus attention drawing activities is paramount. In addition, many interstices that give a barred effect on those windows may suggest that some aspects of familial environment feel like a prison to the child.

AA drew human figures towards the end of therapy (Session 16) (Figure 3). The figure at the right side signifies a child with a sense of accomplishment. Developmentally, this human 
figure matches her current cognitive level compared one drawn in Figure 1.

Emotional well-being can be inferred. A tall and moderate-size figure drawn indicates the child's confidence level which was consistently good throughout sessions. Placing the figure on the right side suggests a well-controlled behaviour. Constant pressure being put on drawing reflects a normal and stable adjustment [14] - AA outstanding progress. Since several sessions mother reported improvement in AA's behaviour. She is a 'different' child now who goes to school regularly, voluntarily helps with the house chores, plays nicely with her siblings with no fight, and importantly is happier.

A firm, unhesitant, and uninterrupted strokes and lines throughout the drawing suggests a secured, self-assured, and assertive personality [14] possibly what AA now experience. AA had gained trust in therapist and therapeutic processes. She feels secure, important, and valuable. She becomes positive, open, and fun towards therapy. The dots she created and later connected to make up the body and legs indicates her planning ability to achieve her goals.

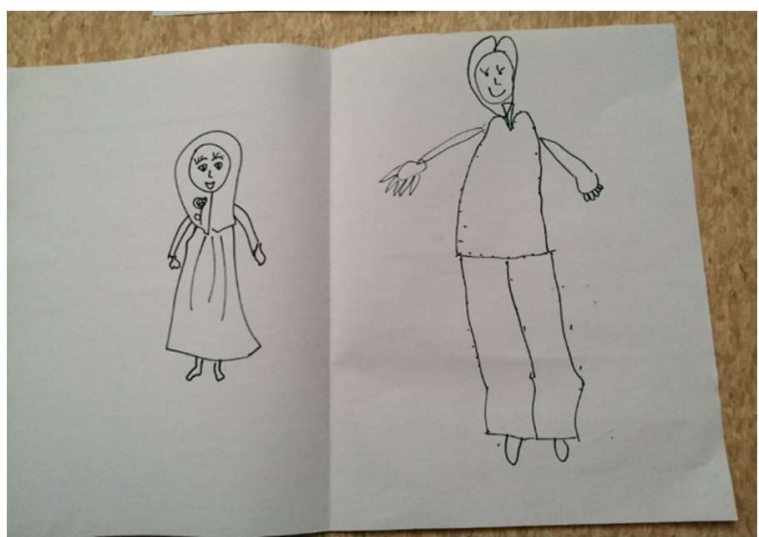

Figure 3. Child's drawing at the end phase of the session

The head, and almost all body parts are proportionate in size. The person is a lady who wears a headscarf and with a pleasant, big smile. These details elements may suggest contented emotion on part of the artist - AA - at least when she drew. The eyes of this person are unusually small and this may indicate contemplative and introspective characteristics [14]. However, the raised eyebrows may suggest contempt or disapprove attitudes towards others or oneself [14]. The other body parts include the torso, two arms and hands with five fingers, legs looked like in a pair of comfortable palazzos, and feet appears appropriate - in size, position, and context. The therapist remembers feeling exhilarated when $A A$ said she indeed drew the therapist! AA then requested therapist to draw her next to that image. It is a great achievement for AA that she is ready and happy to get connected to others.

The SDQ was readministered on mother and teacher after 20 sessions and it reveals consistent findings. Especially for the mother, the scores of problematic behaviours reduced significantly post intervention. Teacher's scores were consistently low (almost no problematic behaviour) yet she addressed the fact that now AA went to school more frequently and tended to join class activities more regularly.

Table 1. The parent and teacher report scores of SDQ at pre and post assessment period

\begin{tabular}{|c|c|c|c|c|}
\hline \multirow{2}{*}{$\begin{array}{l}\text { SDQ scores^ } \\
\text { Component/Time }\end{array}$} & \multicolumn{2}{|c|}{ Mother } & \multicolumn{2}{|c|}{ Teacher } \\
\hline & PRE* $^{*}$ & POST $^{* *}$ & $\mathrm{PRE}^{*}$ & $\mathrm{POST}^{* * *}$ \\
\hline Total Scores & 13 & 5 & 7 & 6 \\
\hline $\begin{array}{l}\text { Prosocial } \\
\text { behaviour }\end{array}$ & 5 & 8 & 5 & 8 \\
\hline Hyperactivity & 3 & 2 & 1 & 0 \\
\hline $\begin{array}{l}\text { Emotional } \\
\text { problems }\end{array}$ & 3 & 0 & 0 & 1 \\
\hline Conduct problems & 5 & 1 & 2 & 0 \\
\hline Peer problems & 2 & 2 & 4 & 5 \\
\hline
\end{tabular}

\footnotetext{
* before session resumes

** after 20 sessions

$\wedge$ Except for Pro Social behaviour, the higher the score, the more problematic behaviour is reported.
}

SDQ: Strength and Difficulties Questionnaires

Mother reported the child has managed to regulate her emotions thus, her anger outburst decreased post sessions. She often played peacefully with siblings too. We witnessed a happier and more talkative child in the playroom too. At the end of therapy, the goals stated by the mother were accomplished. Mother claimed that 
AA was changed from a quiet, asocial, and upset child to a friendly, talkative, and happy girl - who is curious and talks a lot that sometimes mother has difficulty to stop. AA communicates effectively and appropriately, and these are shown from series of drawing she produced throughout the therapy.

\section{Conclusion}

Analysis of drawing provides evident on changes and self-improvement that the child has shown and experienced throughout non-directive therapeutic play session. It informs her psychological standing especially when it is supported with clinical observation during play and reports from significant others such as parent and teacher. However, it does not indicate what aspects or types of play contributes to child's progress and improvement. Indeed, play serve merely as a tool. The main therapeutic components are the presence of and reflection by an effective therapist as well as the child's own psychological readiness to take risk and embrace changes.

\section{Acknowledgement}

The author would like to thank the mother of the child who verbally consented this case to be reported in anonymous way.

\section{References}

[1] McMahon L. The Handbook of Play Therapy and Therapeutic Play. The Handbook of Play Therapy and Therapeutic Play. London: Routledge; 2012.

[2] Axline VM. Dibs in Search of Self : The Renowned, Deeply Moving Story of an Emotionally Lost Child Who Found His Way Back. New York: Random House USA Inc; 1990.

[3] Malchiodi C. Using drawing as intervention with traumatized children. Trauma Loss Res Interv. 2001;1(1):21-8.

[4] Green E. The handbook of Jungian play therapy with children \& adolescents. Baltimore: John Hopkins University Press; 2014.

[5] Burgess AW, Hartman CR. Children's drawings. Child Abus Negl. 1993;17(1):161-8.
[6] 6. Jung C. Memories, dreams, reflections. New York: Vintage Books [Internet]. New York: Vintage Books; 1961. Available from: https://antilogicalism.com/wpcontent/uploads/2017/07/memories-dreamsreflections.pdf

[7] Allan J. Inscapes of the child's world: Jungian counseling in schools and clinics. Dallas, TX: Spring Publications; 2020.

[8] 8. Allan J, Bertoia J. Written pathways to healing: Education and Jungian child counseling. Dallas, TX: Spring Publications; 1992.

[9] Green E. Activating the self-healing archetype in children affected by sexual abuse. Assoc Play Ther Newsl. 2004;23(4):19-20.

[10] Benveniste D. Recognizing defenses in the drawings and play of children in therapy. Psychoanal Psychol. 2005;22(3):395-410.

[11] Furth $G$. The secret world of drawings: $A$ Jungian approach to healing through art. Toronto: Inner City Books; 2002.

[12] Malchiodi C. Understanding children's drawings. New York: Guilford Publications, Inc; 1998.

[13] Malchiodi C. Handbook of art therapy. New York: Guilford Publications, Inc; 2003.

[14] Ward O. Multilevel Analysis of Projective Drawings (MAPD) - Instructional Manual for Clinical Use [Internet]. [cited 2021 Jan 10]. Available from: https://www.scribd.com/document/4028808 32/Projective-Drawings-1-pdf

[15] Fallahi C. The House Tree Person Test [Internet]. [cited 2021 Jan 10]. Available from: https://prezi.com/tnfyiyevxses/house-treeperson/

[16] Foley YC, Mullis F. Interpreting Children's Human Figure Drawings: Basic Guidelines for School Counselors. Georg Sch Couns Assoc J. 2008;1(1):28-37.

[17] Idris IB, Barlow J, Dolan A, Surat S. The Reliability and Validity of the Malay ParentReport Version of the Strengths and Difficulties Questionnaire. Malaysian J Med Sci [Internet]. 2021;28(1):125. Available from: https://dx.doi.org/10.21315\%2Fmjms2021.28 .1 .18

[18] Goodman R. The strengths and difficulties questionnaire: a research note. J Child Psychol Psychiatry [Internet]. 1997;38(5):5816. Available from: 
https://dx.doi.org/10.1111/j.1469-

7610.1997.tb01545.x

[19] Jephcott M. Play therapy UK [Internet].

Available from:

https://playtherapy.org.uk/register/ 